\title{
Non-Palpable Invasive Lobular Carcinoma Initially Diagnosed by Inguinal Lymph Node Biopsy
}

\author{
Mohammad Zuhdy, Mona Zaky, Reham Alghandour, Gena Abdelazeem, Omar Hamdy, Abdelhadi Shebl \\ Mansoura University, Egypt
}

Correspondence to: Dr. Omar Hamdy; Email: omarhamdy87@gmail.com.

\section{Summary}

Metastasis from breast cancer to the inguinal lymph nodes or the vulva is a rare event with very few cases reported in literature. A 38-year-old lady presented complaining of progressive abdominal enlargement. Physical examination was unremarkable apart from abdominal enlargement and enlarged right inguinal lymph node. Radiology showed marked ascites, omental thickening, bilateral small ovarian masses, suspicious right inguinal lymph node (LN) as well as breast fibrocystic disease. Cytological examination of the ascitic fluid revealed malignant cells. Core needle biopsy from the inguinal LN suggested metastatic breast carcinoma. Breast MRI showed heterogeneous fibro-glandular tissue and moderate parenchymal enhancement. Random core needle biopsies from the breast led to the diagnosis of invasive lobular carcinoma. The patient received 8 cycles of docetaxel/carboplatin protocol, with partial response. Next, she was maintained on hormonal treatment

\section{Introduction}

The common sites of nodal metastases from breast cancer are the axilla, supraclavicular and infraclavicular fossae, the mediastinum and the internal mammary chain. Metastasis to the inguinal lymph nodes is very rare (1).

We present a patient with non-palpable invasive lobular carcinoma diagnosed by biopsy of an inguinal lymph node, which was confirmed by multiple random core biopsies from the breast. The patient later developed multiple vulvar metastases.

\section{Case report}

A 38-year-old lady with non-relevant medical or surgical history was referred to our center for oncological assessment from the specialized internal medicine hospital. She complained of progressive abdominal enlargement. Clinical examination revealed diffuse abdominal enlargement with no palpable masses. Breast examination was unremarkable. The right inguinal lymph nodes were palpable. Abdomino-pelvic ultrasonography (Fig. 1) and magnetic resonance imaging (MRI) showed
(Anastrazole) till the ascites re-accumulated. Vulvar nodules appeared whose biopsy revealed infiltration by the same tumoral tissue. She received 6 cycles of Endoxan and Pharmarubicin till regression was achieved, and then she was subjected to Exemestane. Thorough clinical assessment including of all lymph node basins and gynecological assessment are crucial in all breast cancer patients, particularly those with invasive lobular subtypes.

Keywords: Breast neoplasms, Lobular, Vulva, Vulvar metastasis, Neoplasm metastasis

Ann Afr Surg. 2019; 17(2):88-92

DOI: http://dx.doi.org/10.4314/aas.v17i2.11

Conflicts of Interest: None

Funding: None

(C) 2020 Author. This work is licensed under the Creative Commons Attribution 4.0 International License.

no abnormalities apart from marked ascites, omental thickening and bilateral suspicious small ovarian masses, the largest measuring $3.7 \mathrm{~cm}$ in diameter. Tumor markers showed significant elevation (CA 15-3=112 (0-26.4 $\mathrm{U} / \mathrm{mL}),(\mathrm{CA} 125=233(0-35 \mathrm{U} / \mathrm{mL})$. Bilateral mammographic evaluation (Fig.2) revealed bilateral increased density in upper outer quadrants, with focal asymmetry in the right breast upper outer quadrant with no definite mass density, architectural distortion or pathological calcifications.

Ultrasound revealed only bilateral symmetrical heterogeneous background parenchyma with no architectural distortion or masses. Multiple tiny cysts were scattered in the upper outer quadrants of both breasts. Both axillary regions revealed benign-looking axillary lymph nodes. The final conclusion was bilateral early fibrocystic disease (BIRADS 2). Inguinal ultrasonography revealed enlarged right inguinal lymph nodes showing distorted shape and lost hilum. Cytological examination of the ascitic fluid revealed malignant cells. Core needle biopsy from the enlarged 
right inguinal lymph nodes (Fig. 3) revealed cores of lymphoid tissue and mature fatty tissue infiltrated by cords and clusters of malignant epithelial cells separated by desmoplasia. Immunohistochemical studies (on the core needle biopsy not the ascitic fluid) were positive for cytokeratin (CK), estrogen receptor (ER), progesterone receptor (PR) and mammoglobin, and negative for CK20, Wilm's tumor-1 and inhibin, suggesting metastatic carcinoma of breast origin.

Ultrasound-guided core needle biopsy on areas of breast parenchymal heterogeneity was negative for malignancy. Dynamic postcontrast breast MRI (Fig. 4) revealed heterogeneous fibro-glandular tissue and moderate background parenchymal enhancement with no definite masses, non-mass like enhancement or enhancing foci.

Multidisciplinary team discussion requested random core needle biopsy from both breasts. Microscopic examination of the biopsy (Fig. 5) revealed cords of discohesive atypical cells invading fat, showing positive staining for CK. This led to the diagnosis of invasive lobular carcinoma. The final staging was stage IV.

For nearly three years, the patient received palliative treatment. She received 8 cycles of docetaxel/carboplatin protocol with good response in resolving the ascites and omental thickening, but with stationary course in inguinal, iliac lymph nodes and bilateral ovarian masses, though CA15-3 and CA 125 normalized. According to RECIST criteria, this response was considered as partial response (PR). The patient was maintained on hormonal treatment (anastrazole) for about one year. However, the disease progressed with ascites re-accumulation; cytological assessment of the fluid revealed malignant cells. Vulvar nodules appeared whose biopsy revealed infiltration by the same malignant tumoral tissue formed of cords of atypical cells with increased nuclear/cytoplasmic (N/C) ratio, pleomorphism and hyperchromatic nuclei arranged in Indian file pattern (Fig. 6).

Immunohistochemistry for CK and ER showed positive reaction in neoplastic cells, and for mammaglobin and progesterone receptor showed focal positive reaction. The patient received 6 cycles of Endoxan and Pharmarubicin and regression was achieved, after which she was put on Exemestane since February 2019 till her last visit in September 2019.

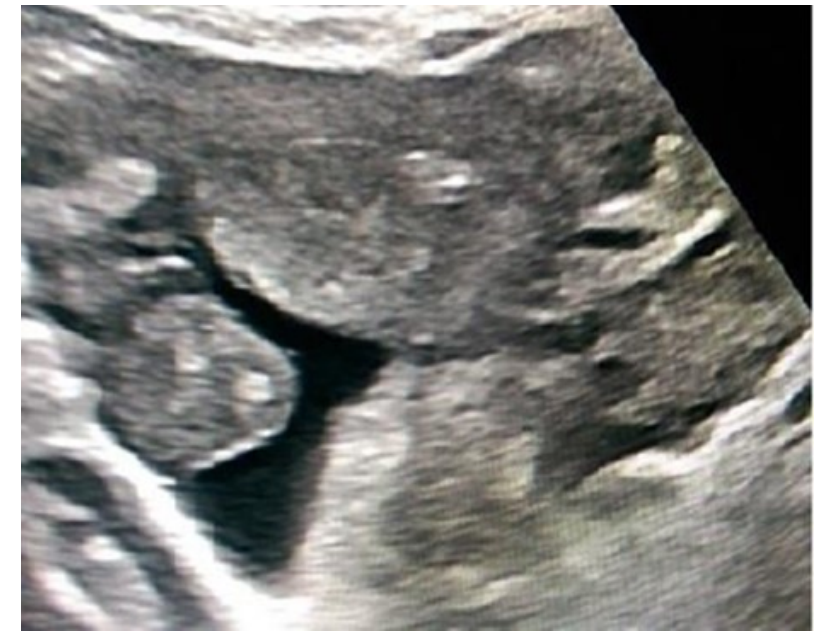

Figure 1: Pelvic U/S showing ascites and bilateral complex cystic adnexal masses.

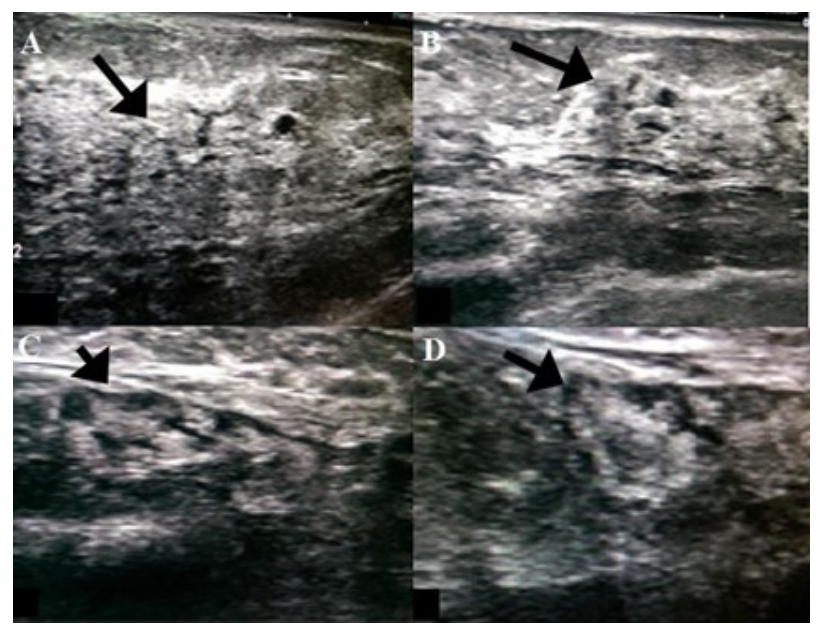

Figure 2: Ultrasonographic images of both breasts and axilla: Right (A) and left (B) breasts showing bilateral early fibrocystic changes with no definite masses or architectural distortion. Right (C) axillary LN and left (D) axillary LNs with preserved shape and hila.

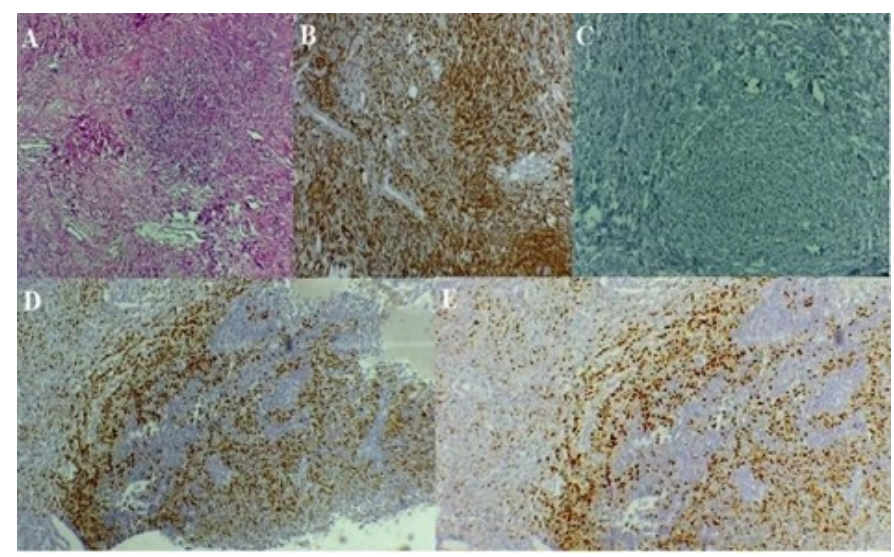

Figure 3: Microscopic picture of the inguinal LN core needle biopsy. A - hematoxylin and eosin (H\&E.); B - positive cytoplasmic staining for $\mathrm{CK}$; $\mathrm{C}$ - positive nuclear staining for $\mathrm{ER}$; D - positive nuclear staining for PR; E - positive nuclear staining for mammaglobin. 


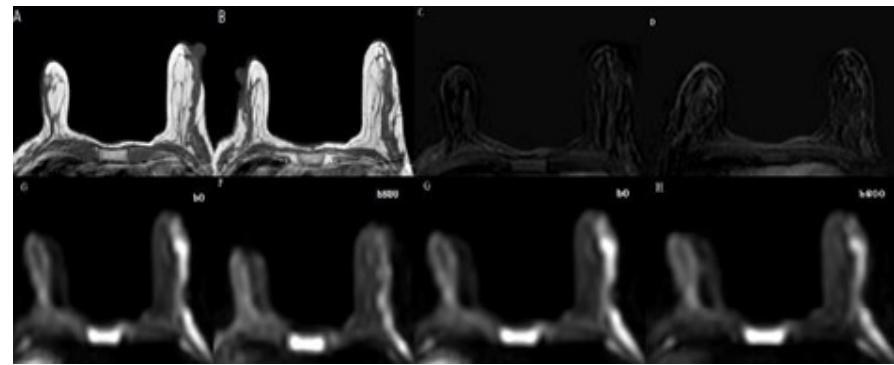

Figure 4: Pre- and post-contrast bilateral breast MRI non-contrast T1WI. A and B show normal fibrofatty glandular parenchyma of breasts; (C) subtracted images; (D) no masses, mass-like or foci of abnormal enhancements. Diffusion-weighted images (E), (F), (G), $(\mathrm{H})$ at low and high $b$ values show no restriction.

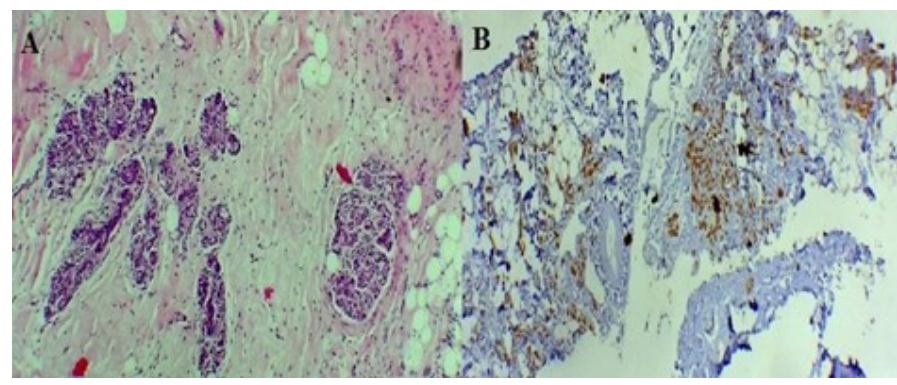

Figure 5: A - core needle biopsy from the breast stained by H \& $\mathrm{E}$; B- positive staining for CK.

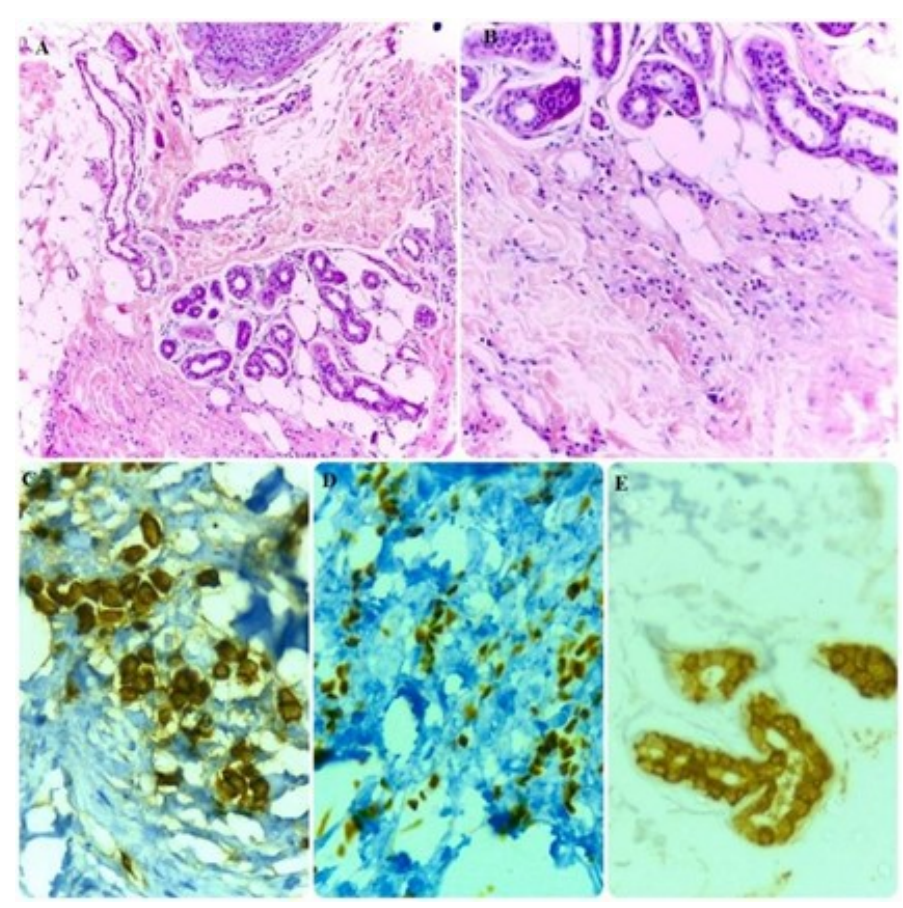

Figure 6: Biopsy from vulvar lesion. A - The dermis is infiltrated by scattered and line arranged malignant cells (H\&E original magnification $\times 10$ ); B - infiltration in the form of Indian file pattern of malignant cells loosely dispersed throughout a fibrous matrix (H\&E original magnification $\times 20$ ); $\mathrm{C}-$ positive cytoplasmic staining of $\mathrm{CK}$ in malignant cells. D - positive nuclear staining of ER in malignant cells; E - focal positive cytoplasmic staining of mammoglobin in malignant cells.

\section{Discussion}

Invasive lobular carcinoma is the second most common type of breast cancer, accounting for $5-15 \%$ of invasive breast cancer subtypes (2). In contrast to invasive ductal carcinoma, the lobular type is characterized by the unusual pattern of metastasis to serosal surfaces, gastrointestinal tract and retroperitoneum (3).

Available radiology tools such as ultrasound, mammogram and MRI have limitations in the diagnosis of ILC. Although MRI has a higher sensitivity than mammography, it is still less accurate in detecting ILC than other invasive cancers. The lower accuracy may be because ILC shows only subtle enhancement and its distribution mimics that of normal breast parenchyma $(4,5)$. In our case, the radiological appearance of both breasts was not suggestive of malignancy; core biopsies from inguinal lymph node and random breast biopsy led to the diagnosis. We consider these findings to be reported for the first time. Pathological diagnosis of an invasive lobular carcinoma can be difficult because this tumor is characterized by small relatively uniform cells that invade the surrounding tissue, with a weak desmoplastic reaction. This could be misleading in the absence of a clinically evident primary tumor (6). Invasive lobular carcinoma cells lack cohesiveness due to inactivation of E-cadherin, which eventually leads to early and unusual pattern of metastasis even before diagnosis of the primary tumor (7). This lack of cohesiveness could explain why our patient presented with ascites, ovarian lesions and inguinal lymphadenopathy despite clinically and radiologically normal breast that was initially negative, even by ultrasound-guided biopsy. This, also, may explain how the random biopsies led to the diagnosis. Either the time between the two biopsies was sufficient for the tumor to progress, or the heterogeneous areas described by ultrasonography were not affected by the tumor. Human error by the radiologist in performing the biopsy may be an explanation as well.

Breast cancer metastasis to the non-regional lymph nodes - mediastinal, retroperitoneal or pelvic - is uncommon. Till now, inguinal lymph node metastasis from breast cancer is rarely reported in English literature (8). Several pathways had been proposed to explain this unusual pattern of metastasis: through the skin and subcutaneous tissue, retrograde spread through submuscular fascia due to blockage of axillary lymphatics, altered lymphatic pathway, or presence of ectopic breast tissue in the vulva $(9,10)$ 
To the best of our knowledge, eight cases of inguinal lymph node metastasis from breast cancer have been reported in English literature. Table 1 summarizes the clinicopathological data of the reported cases.

Skin metastasis may be encountered in $0.2-9 \%$ of autopsy specimens of patients with a known malignancy, reported either synchronously, metachronously or even as the initial presentation. Skin metastasis was most commonly reported with breast and lung carcinomas, with a reported incidence in breast carcinoma reaching up to $23.9 \%(11,12)$. It was most commonly encountered on chest wall and lateral trunk, and may be due to either direct invasion, local or distant metastasis (13). In our case, the metastatic cutaneous lesions were nodular and were present on the vulva and medial aspect of the thigh. This finding is interesting as vulvar secondaries are considered a rare event, accounting for $5-8 \%$ of all vulvar cancers. In their study in 2003, Neto et al. (14) reported 4 cases $(6 \%)$ of vulvar metastasis from primary breast origin out of 66 cases (14). To the best of our knowledge, this is the twenty third reported case of vulvar metastasis from breast cancer, and the sixth of invasive lobular subtype (15-17).

Table 1: Summary of clinicopathological data of reported cases

\begin{tabular}{|c|c|c|c|c|}
\hline $\begin{array}{l}\text { Author, } \\
\text { Year }\end{array}$ & $\begin{array}{l}\text { Cancer type \& } \\
\text { molecular } \\
\text { biology }\end{array}$ & $\begin{array}{l}\text { Primary/ } \\
\text { recurrent }\end{array}$ & Treatment & $\begin{array}{l}\text { Other } \\
\text { metastasis }\end{array}$ \\
\hline Baba (9) & $\begin{array}{l}\text { Tubular } \\
\text { carcinoma, ER } \\
\& \text { PR negative }\end{array}$ & Primary & $\begin{array}{l}\text { Chemo- } \\
\text { radiotherapy } \\
\text { (CRT) }\end{array}$ & No \\
\hline $\begin{array}{l}\text { Kilciksiz } \\
\text { (18) }\end{array}$ & $\begin{array}{l}\text { Duct } \\
\text { carcinoma, ER } \\
\& \text { PR negative }\end{array}$ & Recurrent & $\begin{array}{l}\text { CRT+ } \\
\text { hormonal }\end{array}$ & $\begin{array}{l}\text { Iliac \&para- } \\
\text { aortic }\end{array}$ \\
\hline $\begin{array}{l}\text { Jebbin } \\
\text { (1) }\end{array}$ & $\begin{array}{l}\text { Lobular } \\
\text { carcinoma } \\
\text { N/A }\end{array}$ & Primary & $\begin{array}{l}\text { Chemo- } \\
\text { therapy }\end{array}$ & No \\
\hline $\begin{array}{l}\text { Jebbin } \\
\text { (1) }\end{array}$ & $\begin{array}{l}\text { Duct } \\
\text { carcinoma, } \\
\text { N/A }\end{array}$ & Primary & $\begin{array}{l}\text { Patient } \\
\text { refused }\end{array}$ & $\begin{array}{l}\text { Supraclavicul } \\
\text { ar LNs \&iliac } \\
\text { mass }\end{array}$ \\
\hline $\begin{array}{l}\text { Goyal } \\
(8)\end{array}$ & $\begin{array}{l}\text { Carcinoma } \\
\text { with apocrine } \\
\text { diff, ER \& PR } \\
\text { negative }\end{array}$ & Recurrent & CRT & No \\
\hline Juel (19) & $\begin{array}{l}\text { Lobular } \\
\text { carcinoma, } \\
\text { Luminal B }\end{array}$ & Recurrent & $\begin{array}{l}\text { Chemotherap } \\
\mathrm{y}+\text { hormonal }\end{array}$ & $\begin{array}{l}\text { Bone } \\
\text { metastasis }\end{array}$ \\
\hline $\begin{array}{l}\text { Al- } \\
\text { Mansour } \\
\text { i (20) }\end{array}$ & $\begin{array}{l}\text { N/A, Luminal } \\
\text { B }\end{array}$ & Primary & CRT & $\begin{array}{l}\text { Pelvic }+ \\
\text { infradiaphrag } \\
\text { matic LNs }\end{array}$ \\
\hline $\begin{array}{l}\text { Ganesh } \\
(21)\end{array}$ & $\begin{array}{l}\text { Lubular } \\
\text { carcinoma, } \\
\text { Triple } \\
\text { negative }\end{array}$ & Recurrent & $\begin{array}{l}\text { Chemo- } \\
\text { therapy }\end{array}$ & $\begin{array}{l}\text { Bone } \\
\text { metastasis }\end{array}$ \\
\hline
\end{tabular}

Thorough clinical assessment including all lymph nodes basin and gynecological assessment are crucial in all breast cancer cases, particularly those with suspected unusual pattern of metastasis such as invasive lobular subtypes.

\section{References}

1. Jebbin N, Adotey J. Metastatic carcinoma of the breast with inguinal lymph node involvement: A report of two cases. Niger J Clin Pract. 2008; 11(4):383-5.

2. Makki J.Diversity of breast carcinoma: Histological subtypes and clinical relevance. Clin Med Insights Pathol. 2015; 8:23-31.

3. Borst M, Ingold J. Metastatic patterns of invasive lobular versus invasive ductal carcinoma of the breast. Surgery. 1993; 114(4):637-42.

4. Brem R, Ioffe M, Rapelyea J, et al.Invasive lobular carcinoma: Detection with mammography, sonography, MRI, and breastspecific gamma imaging. AJR Am J Roentgenol. 2009; 192(2):379-83.

5. Mann R, Hoogeveen Y, Blickman J, et al. MRI compared to conventional diagnostic work-up in the detection and evaluation of invasive lobular carcinoma of the breast: A review of existing literature. Breast Cancer Res Treat. 2008; 107(1):1-14.

6. Kobayashi T, Shibata K, Matsuda Y, et al. A case of invasive lobular carcinoma of the breast first manifesting with duodenal obstruction. Breast Cancer. 2004; 11(3):306-8.

7. Berx G, Cleton-Jansen A, Strumane K, et al. E-cadherin is inactivated in a majority of invasive human lobular breast cancers by truncation mutations throughout its extracellular domain. Oncogene. 1996; 13(9):1919-25.

8. Goyal S, Puri T, Julka P. Breast cancer with inguinal node recurrence. J Egypt Natl Canc Inst. 2015; 27(1):41-3.

9. Baba M, Tatsuta M, Miya A, et al. A case of breast cancer diagnosed by inguinal lymph node metastasis. Breast Cancer. 2000; 7(2):173-5.

10. McMaster J, Dua A, Dowdy S.Primary breast adenocarcinoma in ectopic breast tissue in the vulva. Case Rep Obstet Gynecol. 2013; (2013):721696.

11. Kamińska-Winciorek G, Wydmański J. Dermoscopy of skin metastases from breast cancer and of the orange peel type ("peau d'orange"): A report of two cases. Int J Dermatol. 2015; 54(3):343-6.

12. Nava G, Greer K, Patterson J, et al. Metastatic cutaneous breast carcinoma: A case report and review of the literature. Can J Plast Surg. 2009; 17(1):25-7.

13. Gül Ü, Kiliç A, Gönül M, et al. Spectrum of cutaneous metastases in 1287 cases of internal malignancies: A study from Turkey. Acta Derm Venereol. 2007; 87(2):160-2

14. Neto A, Deavers M, Silva E, et al. Metastatic tumors of the vulva: A clinicopathologic study of 66 cases. Am J Surg Pathol. 2003; 27(6):799-804.

15. Al Zuhair A, Al Aqeel S, Al Essa A, et al. Synchronous vulvarbreast cancer metastasis case Report and review of the literature. Women's Health Gynecol. 2016; 2(8).

16. Alligood-Percoco N, Kessler M, Willis G. Breast cancer metastasis to the vulva 20 years remote from initial diagnosis: A 
case report and literature review. Gynecol Oncol Rep. 2015; 13:33-5.

17. Gandhi A, Roy S, Mridha A, et al. Vulvar metastasis from carcinoma breast unveiling distant metastasis: Exploring an unusual metastatic pattern. J Egypt Natl Canc Inst. 2015; 27(4):243-6.

18. Kilçiksiz S, Gökçe T, Kinay M. Isolated inguinal lymph node metastasis from breast carcinoma-Case report and review of the literature. J BUON. 2006; 11(2):229-32.
19. Juel J, Harving F, Pareek M. Symbiotic lymph node metastasis from breast cancer and melanoma. Case Reports. 2017; 2017:bcr2017.

20. Al-Mansouri L, Poursoltan P, Simons M, et al. Primary breast cancer of the vulva: A case report and literature review. J Obstet Gynaecol Res. 2018; 44(12):2190-4.

21. Yalavarthi G, Arulappan.T, Sivaraja K. A rare case of isolated inguinal lymph node metastasis from breast carcinoma-Case report. J Med Sci Clin Res. 2019; 7(1):1167-70. 